\title{
Method for Reducing the Number of Wild Animal Monitors by Means of Kriging
}

\author{
Kohei Arai ${ }^{1}$ \\ ${ }^{1}$ Graduate School of Science and Engineering \\ Saga University \\ Saga City, Japan
}

\author{
Takashi Higuchi ${ }^{1}$ \\ ${ }^{1}$ Graduate School of Science and Engineering \\ Saga University \\ Saga City, Japan
}

\begin{abstract}
Method for reducing the number of wild animal monitors is proposed by means of Kriging. Through wild animal route of simulations with 128 by 128 cells, the required number of wild animal monitors is clarified. Then it is found that the number of wild animal monitors can be reduced based on Kriging by using variograms and semi-variograms among the neighboring monitors. Also, it is found that the number of wild animal monitors by the factor of a by means of the proposed method.
\end{abstract}

Keywords-Kriging; Variogram; Semi-Variogram; Wild animal; Wild pig

\section{INTRODUCTION}

Wildlife damage in Japan is around 23 Billion Japanese Yen a year in accordance with the report from the Ministry of Agriculture, Japan. In particular, wildlife damages by deer and wild pigs are dominant (10 times much greater than the others) in comparison to the damage due to monkeys, bulbuls (birds), rats. Therefore, there are strong demands to mitigate the wildlife damage as much as we could. It, however, is not so easy to find and capture the wildlife due to lack of information about behavior. For instance, their routes, lurk locations are unknown and not easy to find. Therefore, it is difficult to determine the appropriate location of launch a trap. On the other hand, it is also difficult to reduce the number of wild animal monitors.

According to the West, B. C., A. L. Cooper, and J. B. Armstrong. 2009. Managing wild pigs: A technical guide. Human-Wildlife Interactions Monograph $1: 1-55^{1}$, there are the following wild pig damages,

1) Ecological:

Impacts to ecosystems can take the form of decreased water quality, increased propagation of exotic plant species, increased soil erosion, modification of nutrient cycles, and damage to native plant species [1]-[5].

2) Agricultural Crops:

Wild pigs can damage timber, pastures, and, especially, agricultural crops [6]-[9].

\section{3) Forest Restoration:}

Seedlings of both hardwoods and pines, especially longleaf pines, are very susceptible to pig damage through direct consumption, rooting, and trampling [10]-[12].
4) Disease Threats to Humans and Livestock:

Wild pigs carry numerous parasites and diseases that potentially threaten the health of humans, livestock, and wildlife [13]-[15].

Humans can be infected by several of these, including diseases such as brucellosis, leptospirosis, salmonellosis, toxoplasmosis, sarcoptic mange, and trichinosis. Diseases of significance to livestock and other animals include pseudorabies, swine brucellosis, tuberculosis, vesicular stomatis, and classical swine fever [14], [16]-[18].

There also are some lethal techniques for damage managements. One of these is trapping. It is reported that an intense trapping program can reduce populations by 80 to $90 \%$ [19]. Some individuals, however, are resistant to trapping; thus, trapping alone is unlikely to be successful in entirely eradicating populations. In general, cage traps, including both large corral traps and portable drop-gate traps, are most popular and effective, but success varies seasonally with the availability of natural food sources [20]. Cage or pen traps are based on a holding container with some type of a gate or door [21]. Also, a method for estimate and predict total number of wild animals by using blog and tweet information instead of counting method by means of wild animal monitors [22].

The method proposed here is to reduce the number of wild animal monitors by means of $\mathrm{Kriging}^{2}$ based on variogram and semi-variogram between the neighboring monitors. Then the time series of images at the designated time is interpolated with the adjacent images. In this process, nonlinear control lines are created in accordance with Kriging [23]-[36] method. It is well known that Kriging does work for interpolations of images [37]. Traps, cages and wild animal detection monitors are costly. Therefore, it is valuable to reduce the number of wild animal monitors. It would be possible to reduce the number of monitors by using interpolations based on Kriging.

The following section describes the method for Kriging followed by the method of simulations. Then the simulation results are described together with some remarks. Finally, conclusion is described together with some discussions.

${ }^{1}$ www.berrymaninstitute.org/publications,

${ }^{2}$ http://en.wikipedia.org/wiki/Kriging 


\section{PROPOSED METHOD}

\section{A. Kriging Method}

Kriging method allows estimation of future point locations with known point locations probabilistically. If only one known point location used, then future point location is exactly same location. If we know that a future point is situated at the center of two known points, the future points are situated at the point of median. Thus the future point, $\hat{y}\left(X_{\circ}\right)$ is estimated with equation (1) by using the known points, $y\left(X_{j}\right)$.

$$
\hat{y}\left(X_{\circ}\right)=\sum_{j=1}^{n} \lambda_{j} y\left(X_{j}\right)
$$

$\lambda_{j}$ can be determined with the condition of equation (2) minimizing equation (3)

$$
\begin{aligned}
& \sum_{j=1}^{n} \lambda_{j}=1 \\
& V_{e}=2 \sum_{j=1}^{n} \lambda_{j} \gamma\left(L_{j \circ}\right)-\sum_{i=1}^{n} \sum_{j=1}^{n} \lambda_{i} \lambda_{j} \gamma\left(L_{i j}\right)
\end{aligned}
$$

where $L_{j \circ}$ is defined as the distance between the future point, 0 and the known points, $\mathrm{j}$ while $L_{i j}$ is defined as the distance in between the known points, $\mathrm{i}$ and $\mathrm{j}$. Meanwhile, estimation error covariance of semi-variogram, $\gamma(L)$ is defined in equation (4).

$$
\gamma(L)=a(1-\exp (b L))
$$

where $a$ and $b$ are coefficients while $L$ denotes distances. Therefore, if the coefficients are determined with the known points, then the distance is known. Thus $\lambda_{j}$ can be determined results in estimation of future points.

The following variogram which is shown in Fig.1 is needed for Kriging (Variogram is a measure which represent spatial correlation between distance and direction of the data in concern.

\section{B. Simulation Method}

Wild animal route simulations are conducted with 128 by 128 cells. Wild animals move from one cell to the other cell. A portion of the simulation cells are shown in Fig.2. Original positions of wild animals are determined by random numbers. After that, wild animals move in accordance another random numbers. On the other hand, wild animal monitors are set on the designated cells regularly. Wild animal monitors are set at every cell in the first trial. Then the number of monitors is reduced by the factor of two. Namely, the monitors are set every two cells in the second trial and the monitors are set every four cells in the third trial and so on.

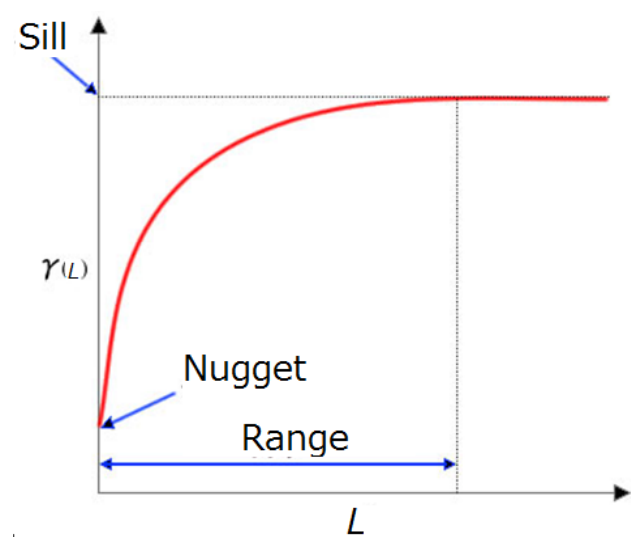

Fig. 1. Variogram which is needed for Kriging

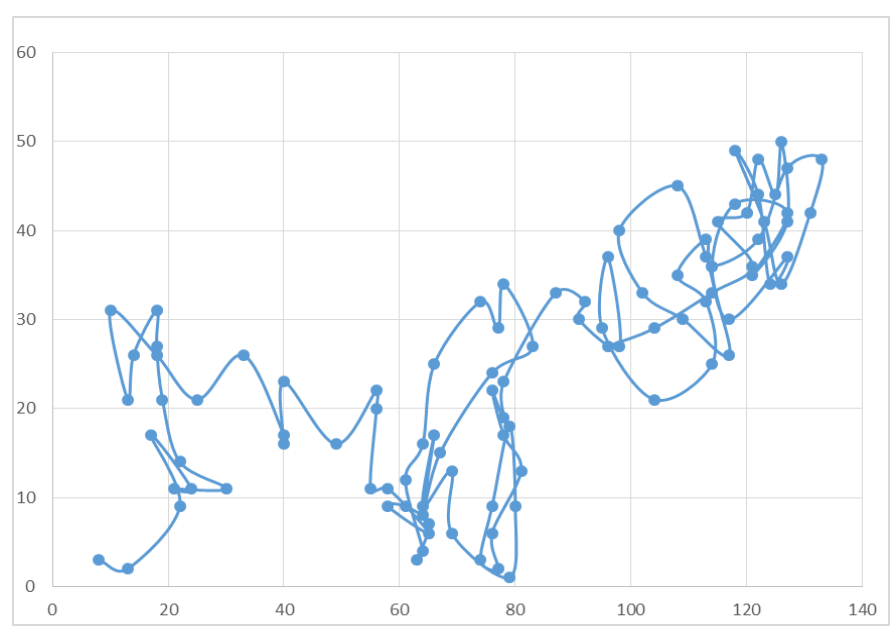

Fig. 2. Portion of simulation cells which consists of 128 by 128

If wild animal reach the cell which is supposed to be a wild animal monitor, then the number of captured wild animals is incremented.

Firstly, variogram has to be calculated for creating of Kriging. After that, the number of monitors is reduced by using the results from the variogram. This is the proposed method for reducing the number of wild animal monitors based on Kriging.

\section{Simulation RESUlts}

\section{A. Relation between the wild animal monitor interval and the number of captured wild animals}

Table 1 shows the relation between the wild animal monitor interval and the number of captured wild animals. In the simulation, 100 wild animal movements is counted for one trial. The monitor interval is one implies that the monitors are set at every cell while the monitor interval is two means that the monitors are set up at every two cells and so on. It is found that the number of total wild animals can be perfectly captured 
in the one trial for the monitor interval is one and two and it is getting down in cases of the interval is more than four as shown in Fig.3. If the acceptable error of the total wild animal estimation is $1 \%$, then the monitor has to be set up at every four cells. It is considerably large resources are required for the monitoring. Therefore, some method for reducing the number of monitors is required. In the simulation physical size of the cell can be arbitrary designed. For instance, $10 \mathrm{~m}$ of cell size would be appropriate for wild pigs.

TABLE I. RELATION BETWEEN THE WILD ANIMAL MONITOR INTERVAL AND THE NUMBER OF CAPTURED WILD ANIMALS

\begin{tabular}{|l|l|}
\hline Monitor Interval(cell) & Number of Captured Animals \\
\hline 1 & 100 \\
\hline 2 & 100 \\
\hline 4 & 99 \\
\hline 8 & 78.8 \\
\hline 16 & 31.3 \\
\hline 32 & 9.14 \\
\hline 64 & 1.91 \\
\hline 128 & 0.4 \\
\hline
\end{tabular}

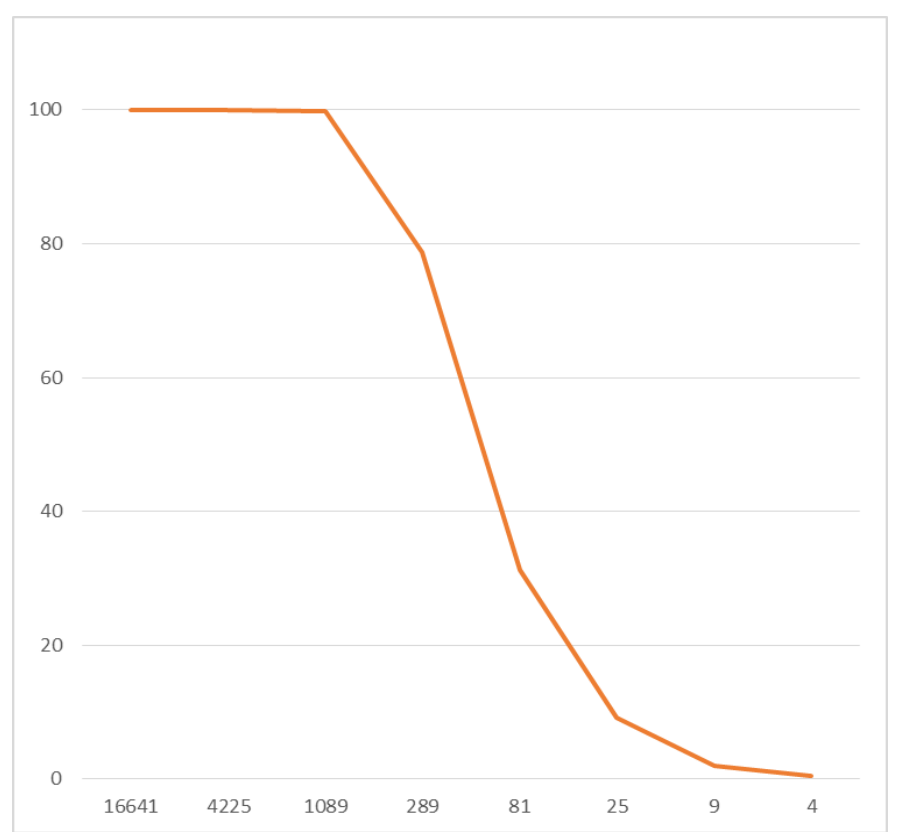

Fig. 3. Number of captured wild animals as a function of the number of wild animal monitors

\section{B. Ssemi-variogram, $\gamma(L)$ and Kriging}

Semi-variogram is calculated for the monitor interval of 32 and 16 as examples. Semi-variograms for the monitor intarevals of 128 and 64 cannot be calculated due to the fact that the number of monitors is too samll. Fig.4 (a) shows one of the examples of the semi-variogram and its approximate function for the monitor interval of 32 while Fig.4 (b) shows its Kriging. Meanwhile, Fig.5 (a) shows one of the examples of the semi-variogram and its approximate function for the monitor interval of 16 while Fig.5 (b) shows its Kriging. These are just examples for those of which the variogram are in the range.

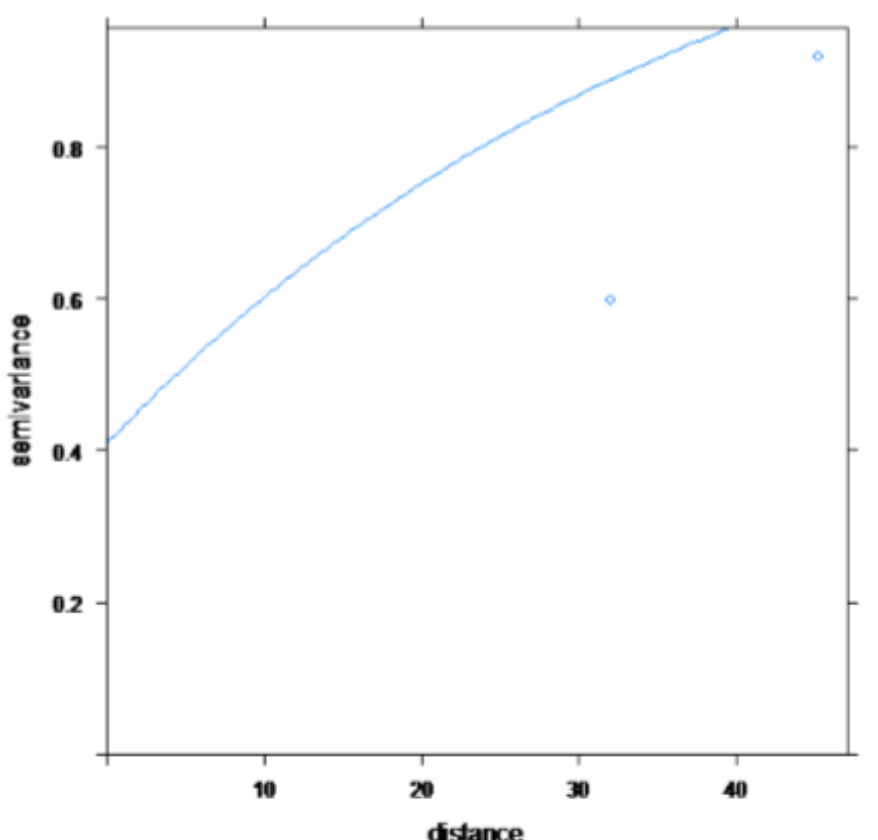

(a)Semi-variogram

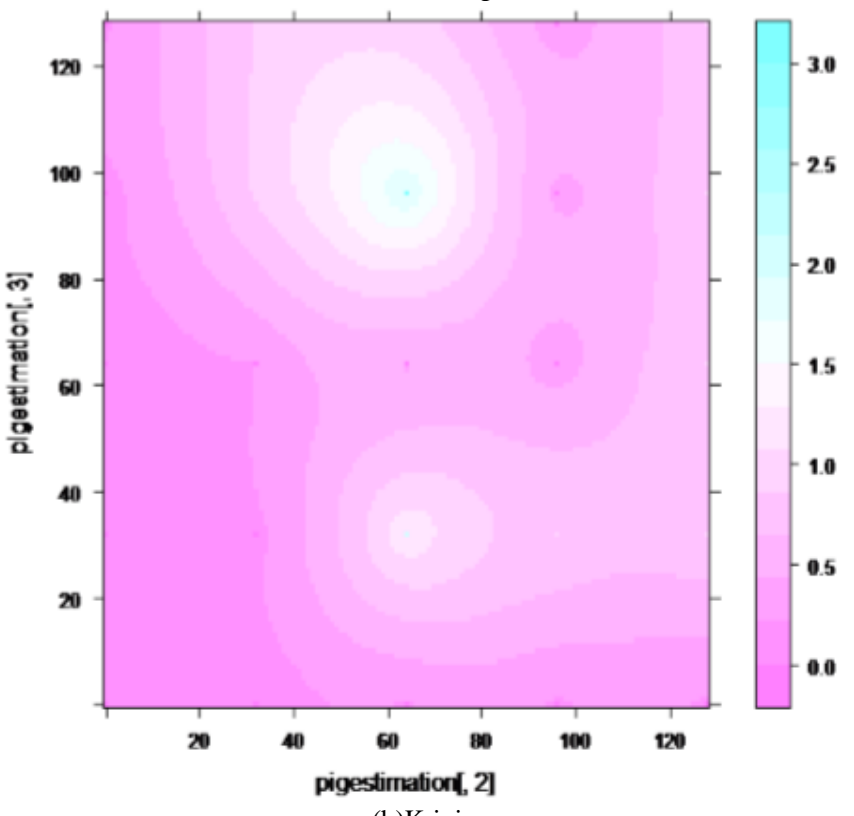

(b)Kriging

Fig. 4. Example of the semi-variogram and Kriging for the monitor interval of 32 for the case correlation is recognizable

These are not always true that all the variograms are situated in the range. Fig.6 (a) shows one of the examples of the semi-variogram for the monitor interval of 16 for the case of which variogram is situated out of range. Fig.6 (b) shows its Kriging. Fig.5 (a) shows the semi-variograms which are in the range (data plots are in the red line) while Fig.6 (a) shows the semi-variograms which are out of the range (data plots are not in the red line). Therefore, it may say that correlation is recognizable for the Kriging in Fig.5 while correlation is not so clear for the Kriging in Fig.6. 


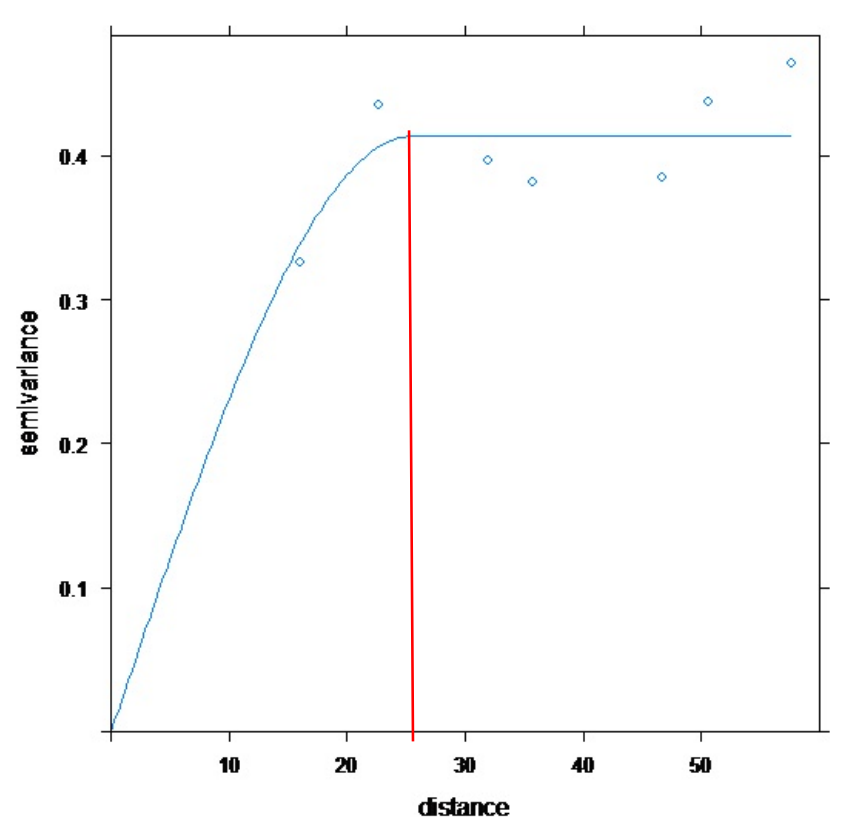

(a)Semi-variogram

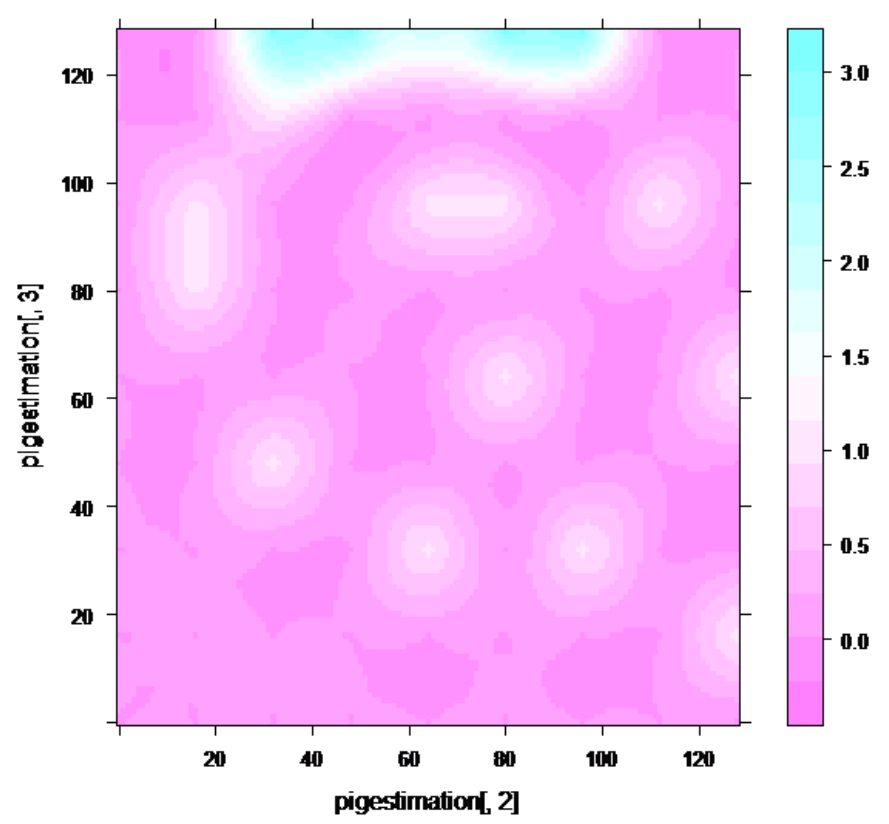

(b)Kriging

Fig. 5. Example of the semi-variogram and Kriging for the monitor interval of 16 when the variougramare in the range

For the case of the correlation is recognizable, standard deviation of semi-variogram is shown in Fig.7 (a) while semivariogram standard deviation for the case of the correlation is not so clear is shown in Fig.7 (b), respectively.

Although the standard deviations for both cases shows the minimum at the cell at which the wild animal monitor is situated (every 16 cells), standard deviation of Fig.7 (a) is higher than those of Fig.7 (b).

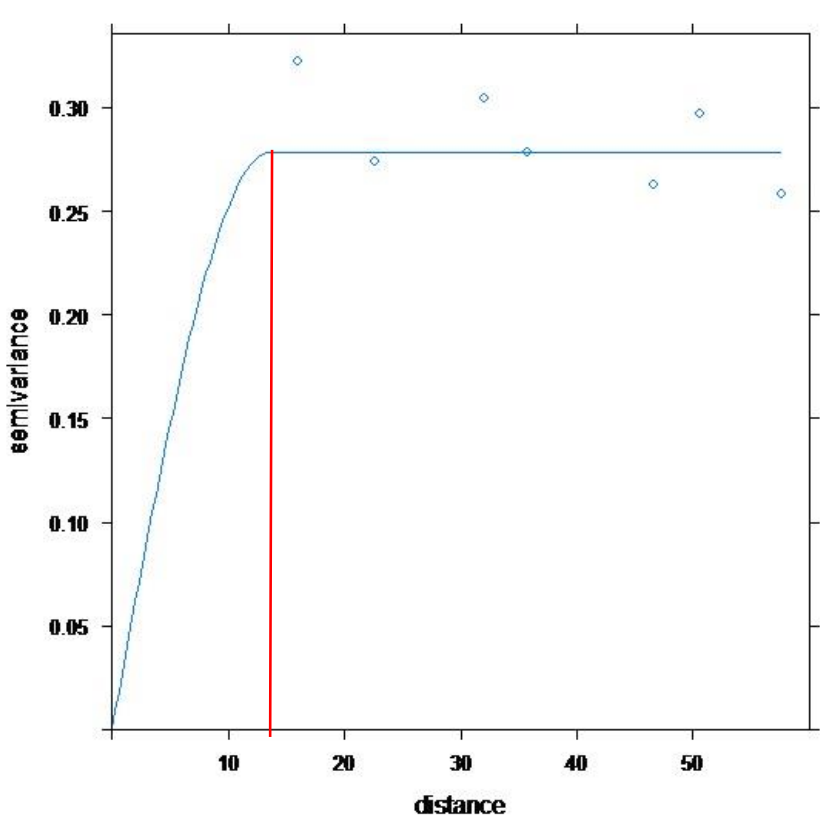

(a)Semi-variogram

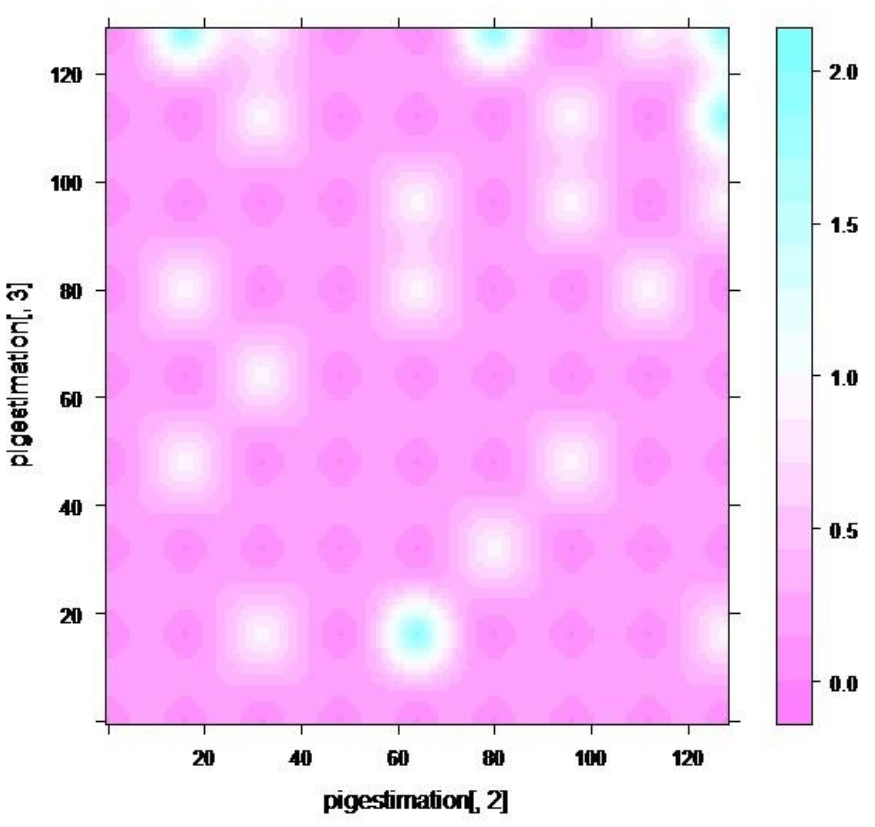

(b)Kriging

Fig. 6. Example of the semi-variogram and Kriging for the monitor interval of 16 when the variogram are out of range

On the other hand, the number of captured wild animals is shown in Fig.8 (a) for the case of correlation is recognizable while that is shown in Fig.8 (b) for the case of correlation is not so clear. These are cross section of the number of captured wild animals along with the horizontal simulation cells. The red line in Fig. 8 shows the number of wild animals is one. Therefore, the number of wild animals is countable for the case of correlation is recognizable while that is not countable for the case of correlation is not so clear. 

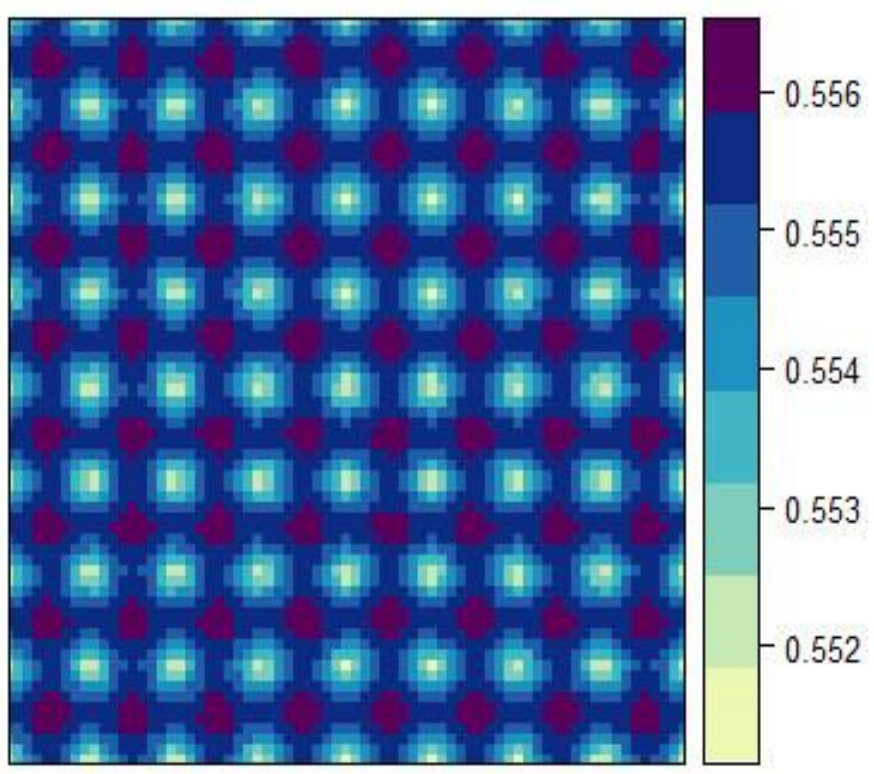

(a)Correlation is recognizable
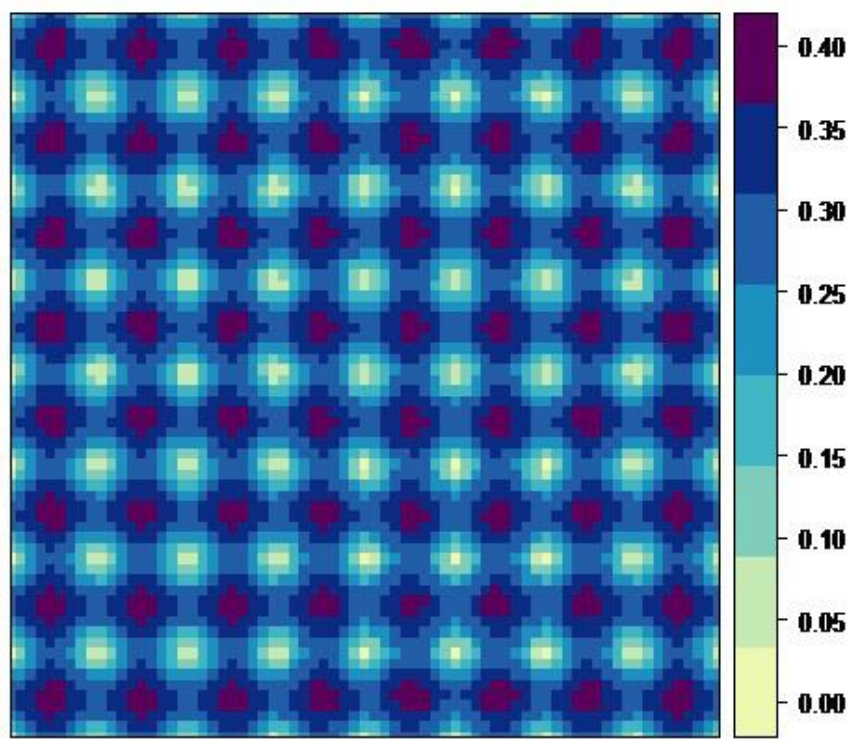

(b)Correlation is not so clear

Fig. 7. Semi-variogram standard deviation for both cases that correlation is recognizable and correlation is not so clear

Actually, the number of data points which shows the number of captured wild animals is more than one is 849 out of 16642 for the case of correlation is recognizable while that of the case of correlation is not so clear is 140 . These results imply that it is possible to estimate the number of the captured wild animals even for the case that wild animal monitors are set up every 16 cells and if the correlation is recognizable while it is difficult to estimate the number of captured wild animals if the correlation is not so clear.

It is concluded that it is possible to estimate the number of wild animals even for the wild animal monitors are set up every 16 cells and if the counted numbers of wild animals between the neighboring monitors have a correlation.

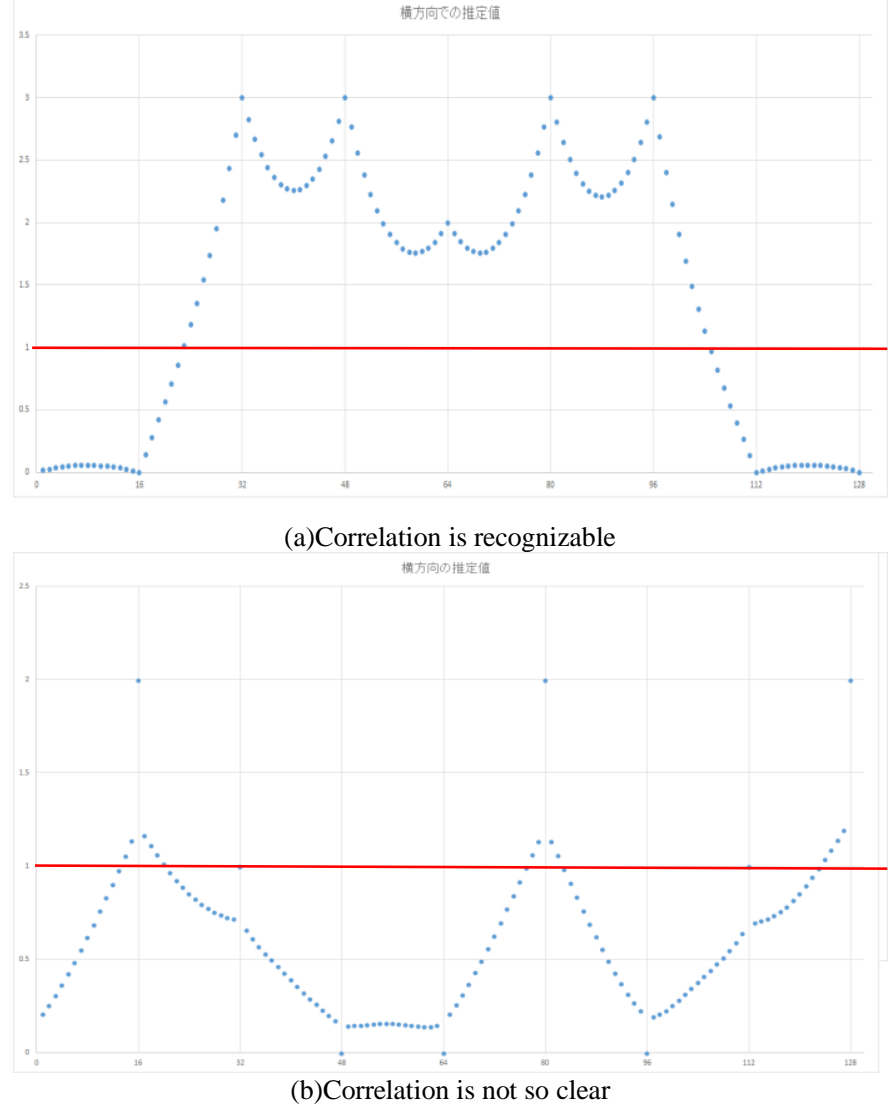

Fig. 8. Horizontal cross section of the number of captured wild animals

Another example for the case that the wild animal monitors are set every 32 cells is shown in Fig.9. Although Fig.4 shows the Kriging for the case that correlation is recognizable, Fig.9 shows the Kriging for the case that correlation is not so clear.

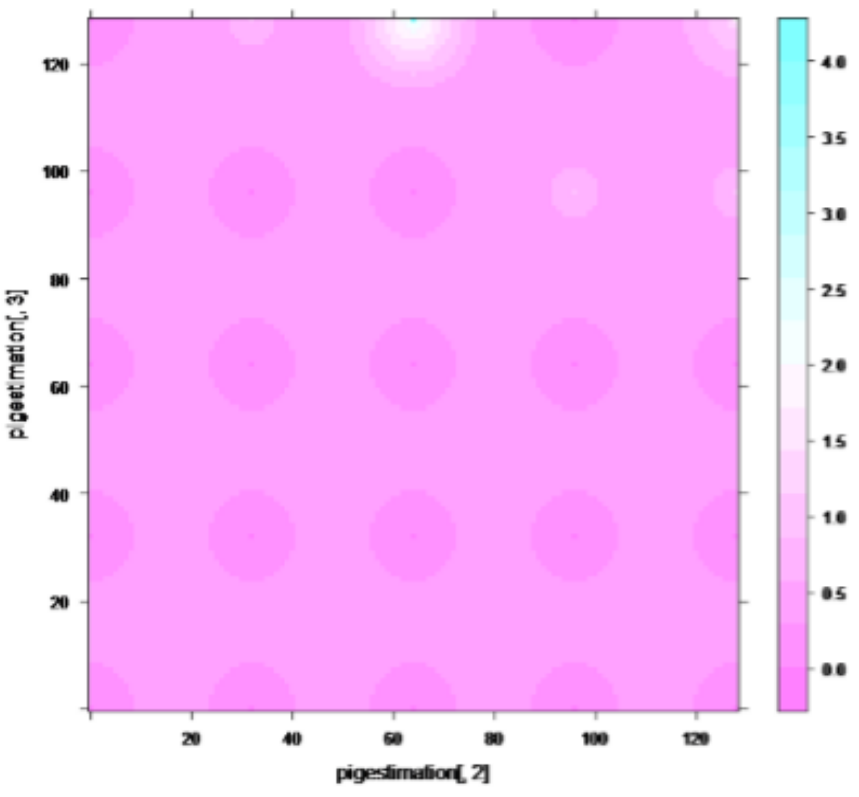

Fig. 9. Kriging for the case that correlation is not so clear and for the wild animal monitors are set every 32 cells 
Therefore, it is not always true that it is possible to estimate the total number of wild animals with the monitors which are set every 32 cells. Fig.10 (a) shows horizontal cross section of the number of captured wild animals for the case that correlation is recognizable while Fig.10 (b) shows that for correlation is not so clear. The number of data points of which the estimated captured wild animals is more than one is 338 for the case that correlation is recognizable while that is 142 for the case that correlation is not so clear. The results imply that it is too difficult to estimated total number of wild animals for the case that the monitors set up every 32 .

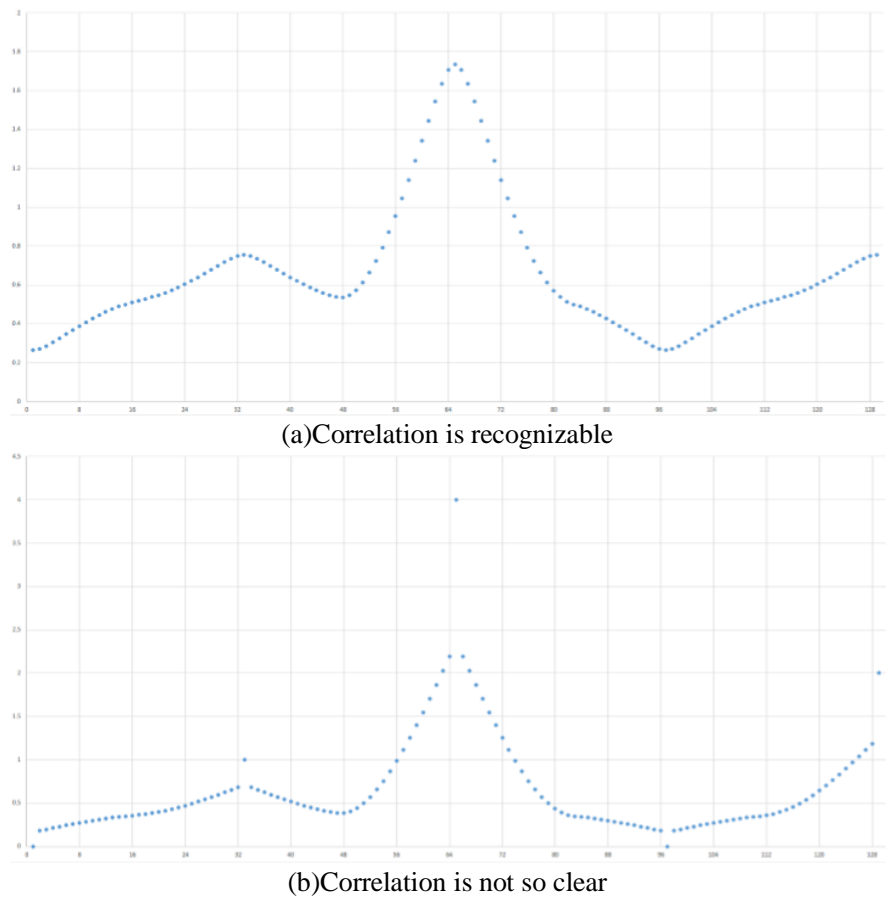

Fig. 10. Horizontal cross section of the number of captured wild animals for the case that correlation is recognizable and that for correlation is not so clear

\section{CONCLUSION}

Method for reducing the number of wild animal monitors is proposed by means of Kriging. Through wild animal route of simulations with 128 by 128 cells, the required number of wild animal monitors is clarified. Then it is found that the number of wild animal monitors can be reduced based on Kriging by using variograms and semi-variograms among the neighboring monitors. Also, it is found that the number of wild animal monitors by the factor of a by means of the proposed method.

As the results from simulations, it is concluded that the number of wild animal monitors can be reduced by the factor of 32 by the proposed Kriging based method. This implies that the monitors are set up every 32 cells that is $320 \mathrm{~m}$ in physical dimension for the $1.28 \mathrm{~km}^{2}$ of the area in concern. The procedure of the proposed method is as follows,

1) Check correlation of captured wild animal numbers between neighboring wild animal monitors

2) Calculated semi-variogram and variogram of the wild animal numbers
3) Calculate Kriging

4) Check standard deviation of estimated captured wild animal number

5) Determine the minimum number of monitors

Further investigation and study is required for checking method of correlations of captured wild animal numbers at the neighboring wild animal monitors.

\section{ACKNOWLEDGMENT}

The authors would like to thank Prof. Dr. Hiroshi Okumura of Saga University for his supports through the experiments.

\section{REFERENCES}

[1] Patten, D. C. 1974. Feral hogs - boon or burden. Proceedings of the Sixth Vertebrate Pest Conference 6:210-234.

[2] Singer, F. J., W. T. Swank, and E. E. C. Clebsch. 1984. Effects of wild pig rooting in a deciduous forest. Journal of Wildlife Management. 48:464-473.

[3] Stone, C. P., and J. O. Keith. 1987. Control of feral ungulates and small mammals in Hawaii's national parks: research and management strategies. Pages 277-287 in C. G. J. Richards and T. Y. Ku, editors. Control of mammal pests. Taylor and Francis, London, England, and New York and Philadelphia, USA.

[4] Cushman, J. H., T. A. Tierney, and J. M. Hinds. 2004. Variable effects of feral pig disturbances on native and exotic plants in a California grassland. Ecological Applications 14:1746-1756.

[5] Kaller, M. D., and W. E. Kelso. 2006. Swine activity alters invertebrate and microbial communities in a coastal plain watershed. American Midland Naturalist 156:163-177.

[6] Bratton, S. P. 1977. The effect of European wild boar on the flora of the Great Smoky Mountains National Park. Pages 47-52 in G. W. Wood, editor. Research and management of wild hog populations. Belle W. Baruch Forest Science Institute, Clemson University, Georgetown, South Carolina, USA.

[7] Lucas, E. G. 1977. Feral hogs - problems and control on National Forest lands. Pages 17-22 in G. W. Wood, editor. Research and management of wild hog populations. Belle Baruch Forest Science Institute, Clemson University, Georgetown, South Carolina, USA.

[8] Thompson, R. L. 1977. Feral hogs on National Wildlife Refuges. Pages 11-15 in G. W. Wood, editor. Research and management of wild hog populations. Belle W. Baruch Forest Science Institute, Clemson University, Georgetown, South Carolina, USA.

[9] Schley, L, and T. J. Roper. 2003. Diet of wild boar Sus scrofa in Western Europe, with particular reference to consumption of agricultural crops. Mammal Review 33:43-56.

[10] Whitehouse, D. B. 1999. Impacts of feral hogs on corporate timberlands in the southeastern United States. Pages 108-110 in Proceedings of the Feral Swine Symposium, June 2-3, 1999, Ft. Worth, Texas, USA.

[11] Mayer, J. J., E. A. Nelson, and L. D. Wike. 2000. Selective depredation of planted hardwood seedlings by wild pigs in a wetland restoration area. Ecological Engineering, 15(Supplement 1): S79-S85.

[12] Campbell, T. A., and D. B. Long. 2009. Feral swine damage and damage management in forested ecosystems. Forest Ecology and Management 257:2319-2326

[13] Forrester, D. J. 1991. Parasites and diseases of wild mammals in Florida. University of Florida Press, Gainesville, Florida, USA.

[14] Williams, E. S., and I. K. Barker. 2001. Infectious diseases of wild mammals. Iowa State University Press, Ames, Iowa, USA.

[15] Sweeney, J. R., J. M. Sweeney, and S. W. Sweeney. 2003. Feral hog. Pages 1164-1179 in G. A. Feldhamer, B. C. Thompson, and J. A. Chapman, editors. Wild mammals of North America. Johns Hopkins University Press, Baltimore, Maryland, USA.

[16] Nettles, V.F., J. L. Corn, G. A. Erickson, and D. A. Jessup. 1989. A survey of wild swine in the United States for evidence of hog cholera. Journal of Wildlife Diseases 25:61-65. 
[17] Davidson, W. R., and V. F. Nettles, editors. 1997. Wild swine. Pages 104-133 in Field manual of wildlife diseases in the southeastern United States. Second edition. Southeastern Cooperative Wildlife Disease Study, Athens, Georgia, USA.

[18] Davidson, W. R., editor. 2006. Wild swine. Pages 105-134 in Field manual of wildlife diseases in the southeastern United States. Third edition. Southeastern Cooperative Wildlife Disease Study, Athens, Georgia, USA.

[19] Choquenot, D. J., R. J. Kilgour, and B. S. Lukins. 1993. An evaluation of feral pig trapping. Wildlife Research, 20:15-22.

[20] Barrett, R. H., and G. H. Birmingham. 1994. Wild pigs. Pages D65-D70 in S. Hyngstrom, R. Timm, and G. Larsen, editors. Prevention and control of wildlife damage. Cooperative Extension Service, University of Nebraska, Lincoln, Nebraska, USA.

[21] Mapston, M. E. 1999. Feral hog control methods. Pages 117-120 in Proceedings of the Feral Swine Symposium, June 2-3, 1999, Fort Worth, Texas, USA.

[22] Arai, K., Indra Nugraha Abdullah, Kensuke Kubo, Katsumi Sugawa, Methods for Wild Pig Identifications from Moving Pictures and Discrimination of Female Wild Pigs Based on Feature Matching Methods, Internationa Journal of Advanced Research in Artificial Intelligence (IJARAI), 4, 8, 18-25, 2015.

[23] Hanefi Bayraktar and F. Sezer. Turalioglu (2005) "A Kriging-based approach for locating a sampling site-in the assessment of air quality, SERRA, 19 (4), 301-305 doi:10.1007/s00477-005-0234-8

[24] Chiles, J.-P. and P. Delfiner (1999) Geostatistics, Modeling Spatial Uncertainty, Wiley Series in Probability and statistics.

[25] Zimmerman, D.A. et al. (1998) "A comparison of seven geostatistically based inverse approaches to estimate transmissivies for modelling advective transport by groundwater flow", Water Resources Research, 34 (6), 1273-1413

[26] Tonkin M.J. Larson (2002) "Kriging Water Levels with a RegionalLinear and Point Logarithmic Drift", Ground Water, 33 (1), 338-353,

[27] Journel, A.G. and C.J. Huijbregts (1978) Mining Geostatistics, Academic Press London

[28] Andrew Richmond (2003) "Financially Efficient Ore Selection Incorporating Grade Uncertainty", Mathematical Geology, 35 (2), 195215

[29] Goovaerts (1997) Geostatistics for natural resource evaluation, OUP. ISBN 0-19-511538-4
[30] X. Emery (2005) "Simple and Ordinary Kriging Multigaussian Kriging for Estimating recoverarble Reserves", Mathematical Geology, 37 (3), 295-31)

[31] A. Stein, F. van der Meer, B. Gorte (Eds.) (2002) Spatial Statistics for remote sensing. Springer. ISBN 0-7923-5978-X

[32] Barris, J. (2008) An expert system for appraisal by the method of comparison';'. PhD Thesis, UPC, Barcelona

[33] Sacks, J. and Welch, W.J. and Mitchell, T.J. and Wynn, H.P. (1989). Design and Analysis of Computer Experiments. 4. Statistical Science. pp. 409-435.

[34] Strano, M. (2008). "A technique for FEM optimization under reliability constraint of process variables in sheet metal forming". International Journal of Material Forming 1: 13-20. doi:10.1007/s12289-008-0001-8. edit

[35] Grace Wahba (1990). Spline Models for Observational Data. 59. SIAM. p. 162.

[36] Williams, Christopher K.I. (1998). "Prediction with Gaussian processes: From linear regression to linear prediction and beyond". In M. I. Jordan. Learning in graphical models. MIT Press. pp. 599-612

[37] Kohei Arai Image prediction method with non-linear control lines derived from Kriging method with extracted feature points based on morphing, International Journal of Advanced Research in Artificial Intelligence, 2, 1, 20-24, (2013)

\section{AutHORS PROFILE}

Kohei Arai, He received BS, MS and PhD degrees in 1972, 1974 and 1982, respectively. He was with The Institute for Industrial Science and Technology of the University of Tokyo from April 1974 to December 1978 also was with National Space Development Agency of Japan from January, 1979 to March, 1990. During from 1985 to 1987, he was with Canada Centre for Remote Sensing as a Post Doctoral Fellow of National Science and Engineering Research Council of Canada. He moved to Saga University as a Professor in Department of Information Science on April 1990. He was a councilor for the Aeronautics and Space related to the Technology Committee of the Ministry of Science and Technology during from 1998 to 2000. He was a councilor of Saga University for 2002 and 2003. He also was an executive councilor for the Remote Sensing Society of Japan for 2003 to 2005. He is an Adjunct Professor of University of Arizona, USA since 1998. He also is Vice Chairman of the Commission "A" of ICSU/COSPAR since 2008. He wrote 34 books and published 520 journal papers. He is now Editor-in-Chief of IJACSA and IJISA. http://teagis.ip.is.saga-u.ac.jp/index.html 